\title{
10 health stories that mattered: June 26-July 3
}

- Accreditation of Canadian medical schools is being changed to reduce influence from the United States and "better reflect Canadian priorities." Though the Committee on Accreditation of Canadian Medical Schools will still consult with the US Liaison Committee on Medical Education on the final decision, the US committee will no longer conduct its own review or write a report.

- Health Canada has revised its position on the health risks of asbestos. Gone are claims that chrysotile is "less potent" than other types of asbestos and that "significant quantities" of the carcinogen must be inhaled to cause harm, bringing Canada's position more in line with that of other developed nations.

- Ontario is looking to increase access to facilities where people can obtain approvals for publicly insured sexreassignment surgery. Currently, the Centre for Addiction and Mental Health in Toronto is the lone site that provides preoperative approvals for Ontario and Newfoundland and Labrador patients.

- Quebec's plan to allow clinics to charge accessory fees to patients for some services will create a two-tier medical system and move the province toward privatization of health care, warn some Quebec health groups. Critics of the fees suggest that clinic owners, doctors and the government should cover the costs or the services should be performed in hospitals.

- Licensed producers of medical marijuana have been receiving requests for cannabis extracts and edibles since the Supreme Court recently overturned a ban on the products, but the companies are not allowed to sell them. Given the negative reaction to the ruling by federal Health Minister Rona Ambrose, some licensed sellers aren't optimistic that Health Canada will amend regulations any time soon.

- Health Canada is seeking feedback on draft regulations that would require controlled-release oxycodone products to have tamper-resistant properties. These products are at high risk of abuse and adding tamper-resistant properties will help fight that problem, stated Health Canada.

- Ontario will change a health secrecy law that permitted hospitals to conduct investigations into medical errors in private, according to Ontario Health Minister Dr. Eric Hoskins. Among changes recommended by an expert panel for the Quality of Care Information Protection Act are allowing patients' families to be involved in reviews of medical errors and granting them the right to call independent investigations.

- There should be greater access to publicly funded psychotherapy, according to Quebec's National Institute for Excellence in Health and Social Services. Research shows that psychotherapy works as well as drugs in treating moderate anxiety or depressive disorders and that it produces longer-lasting benefits and costs less, stated the institute.

- Cracking down on illegal medical marijuana dispensaries in Vancouver is a low priority for the city's police department, stated Chief Adam Palmer. The department is focusing on reducing violent crime and therefore on drugs that are more often associated with violence, such as cocaine, heroin and fentanyl.

- Antibiotic use varies across Ontario nursing homes by a factor of 10 , and residents of high-use facilities are $24 \%$ more likely to have an adverse event related to antibiotics, according to the Institute for Clinical Evaluative Services. Overall, about two-thirds of residents receive antibiotics each year, making it the most common medication administered in nursing homes. - Roger Collier, CMAJ

CMAJ 2015. DOI:10.1503/cmaj.109-5114 